\title{
The Future of Media Interfaces
}

\author{
Joaquim Jorge \\ Instituto Superior Técnico da Universidade de Lisboa \\ jorgej@ieee.org
}

\begin{abstract}
We are living in a post-WIMP world. Indeed, more and more users access information, communicate and operate mobile information appliances foregoing the still common mouse and keyboard of yonder. However, no matter how powerful or elegant the new mobile devices are, it is the user interface that ultimately governs how successful new devices or systems will be. In this lecture I will look at current multimedia systems and their applications to virtual environments and ubiquitous computing. Multimedia user interfaces currently engage people using images, video and sound but virtual environments not only involve interactive 3D graphics, but further need to take more advantage of our senses through spatial audio, haptics and many other novel and exciting communication modalities. This talk will explore key current research issues and future directions up to and before the prophesized singularity.
\end{abstract}

\section{Keywords}

Multimedia Systems, Virtual Environments, Ubiquitous Computing.

\section{SHORT-BIO}

Joaquim Jorge é Professor Catedrático de Computação Gráfica e Multimídia no Departamento de Engenharia Informática do Instituto Superior Técnico da Universidade de Lisboa, Portugal e Coordenador Científico do Grupo de Pesquisa em Visualização e Interfaces Multimodais do Instituto de Engenharia de Computação e Sistemas INESCID. Ele recebeu o bacharelado em Engenharia Eletrotécnica (Licenciatura em Telecomunicações), pelo Instituto Superior Técnico (IST), Lisboa 1984 e Mestrado (1992) e doutoramento (1994) em Ciências da Computação pelo Rensselaer Polytechnic Institute, Troy, NY. Ele recebeu sua habilitação em Computação Gráfica do IST, Universidade Técnica de Lisboa em 2002. As áreas de pesquisa do Dr. Jorge incluem Computação Visual, Modelação Geométrica, Visualização e Interfaces Multimodais Inteligentes e Reconhecimento de Padrões. Ele vem trabalhando em interfaces caligráficas para Modelagem Geométrica e Abordagens Colaborativas para Design Review. Ele é coautor de dois livros, editou outros 14 e publicou mais de 40 artigos revisados por pares em revistas internacionais, além de mais de 150 conferências.

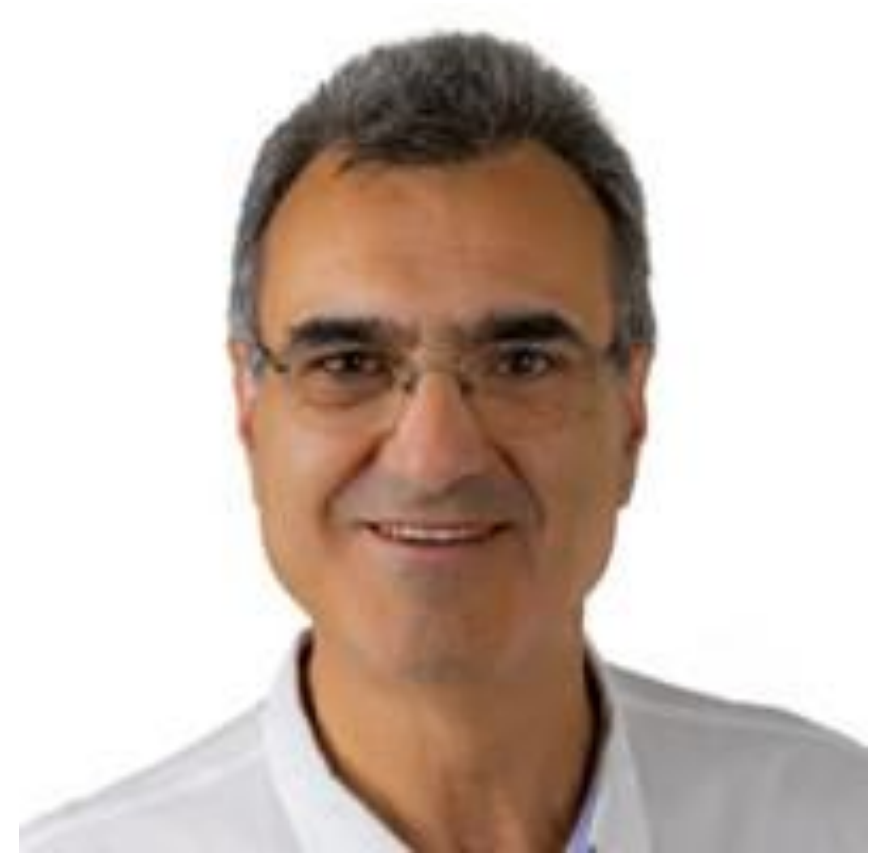

Figure 1. Joaquim Jorge

Permission to reproduce or distribute, in whole or in part, material extracted from this work, verbatim, adapted or remixed, as well as the creation or production from the content of such work, is granted without fee for non-commercial use, provided that the original work is properly credited.

IHC 2019 - Plenárias, Outubro 21-25, 2019, Vitória, Brasil. In Anais Estendidos do XVIII Simpósio Brasileiro sobre Fatores Humanos em Sistemas Computacionais. Porto Alegre: SBC.

(C)2019 by the author(s), in accordance with the terms of the Creative Commons Attribution-NonCommercial 4.0 International Public License (CC BY-NC 4.0) 